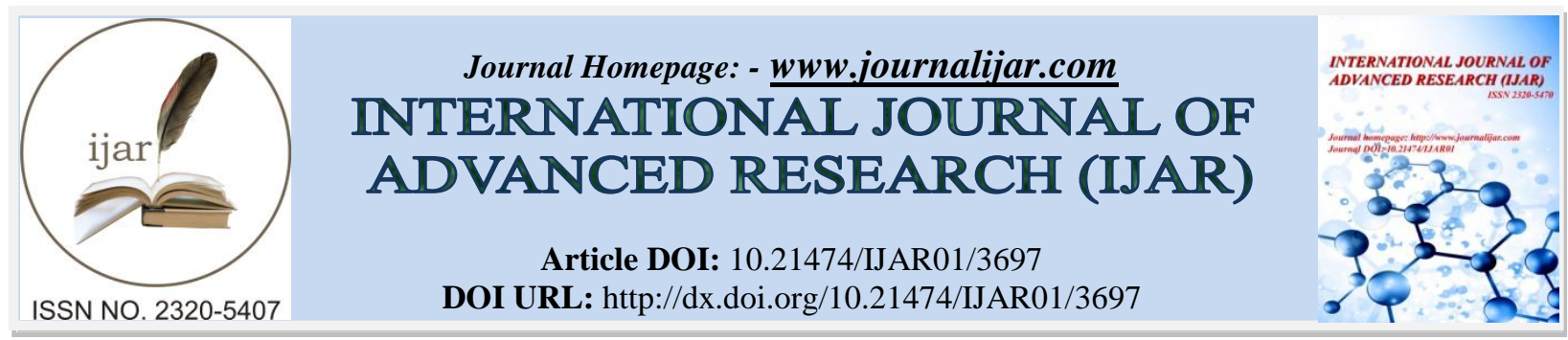

RESEARCH ARTICLE

\title{
UNDERSTANDING THE SOCIODEMOGRAPHIC PROFILE AND LONG TERM COMMUNITY PSYCHOSOCIAL NEEDS OF CHILDREN AND ADOLESCENT SURVIVORS OF A NATURAL DISASTER ONE DECADE AFTER 2005, ‘SNOW-TSUNAMI’ IN KASHMIR.
}

\author{
Huda Mushtaq ${ }^{1, *}$, Sadaqat Rehman ${ }^{2}$, and Shahnawaz Mushtaq. \\ 1. Department of Clinical Psychology, Singhania University Rajasthan. \\ 2. Institute of Mental Health and Neurosciences-Kashmir- Department of Psychiatry, Government Medical \\ College, Srinagar, J \& K, India.
}

\section{Manuscript Info}

[........................

Manuscript History

Received: 14 January 2017

Final Accepted: 02 February 2017

Published: March 2017

Key words:-

Psychosocial problems, Children and Adolescents, Disaster, long term.

\section{Abstract}

Objective: To explore the sociodemographic profile and long term psychosocial needs of children and adolescents survivors of snowstorm disaster who survived a natural disaster (snow storm) in Kashmir more than a decade back.

Methods: It is a cross sectional study done in a disaster affected population of children and adolescents in South Kashmir 10 years after the snow storm disaster. The study was designed as a survey of the sociodemographic and long term psychosocial correlates and mental health status of young adults living in the same vulnerable area today also.

Results: Participants were 139 young adult inhabitants of snow storm stricken area in south kashmir in 2005 (exposed group) and 71 residents of a geographically and enthnoculturally identical population in central Kashmir area. Rampant psychosocial problems among the young disaster survivors long after the disaster, when no one is around to help after the initial knee jerk response of relief agencies, is clearly reflected through the results of our study.

And measures to address them as clearly revealed by our study through an outreach psychosocial and clinical service programme long after the disaster when no one is around to help after the initial knee jerk response of relief agencies is greatly stressed.

Conclusion: The results indicate that disasters can have long-standing adverse effects on survivor's psychosocial well being and mental health even after 10 years later. Post trauma morbidity is more lasting in people with lesser support viz lower socio economic class, rural background and lower education.

Copy Right, IJAR, 2017,. All rights reserved.

\section{Introduction:-}

Though disasters are inevitable part of human existence but increasingly frequent massive disasters and horrendous events over the past decade or so have not only directly impacted many regions of the world but indirectly affected humanity as a whole ${ }^{16}$. 
A disaster is the outcome of an extraordinary occurrence that destroys property, kills people, and produces physical or psychological damage as well as overwhelming the adaptive potential of the social group ${ }^{12}$.

Disasters produce multiple patterns of outcome depending on a combination of risk and resilience factors. ${ }^{2}$ As compared to manmade disasters; natural disasters occur suddenly, usually without warning and kill a large number of people in defined or limited geographical area over a limited period of time.

The consequences of natural disasters are worse and the death toll is greater in developing countries ${ }^{1}$.

Children and adolescents are at a higher risk of becoming victims and suffering the losses resulting from disasters. Recent findings have shown that children's reactions to disasters can be severe and are not merely fleeting, transitory events that quickly dissipate ${ }^{4}$.Often an entire community is impacted, further undermining a child's sense of security and normalcy. These factors present a variety of unique issues and coping challenges, including issues associated with specific types of natural disasters, the need to relocate when home and/or community have been destroyed, the role of the family in lessening or exacerbating the trauma, emotional reactions, and coping techniques ${ }^{11}$.Efforts to provide effective services and interventions for children and adolescents following a disaster therefore represent an important, but frequently overlooked, mental health need.

The northern most state of the country, Kashmir (Jammu and Kashmir) has been regarded as the heaven on earth. Its beauty and hospitable population is legendary. Unfortunately the state has been witnessing a continuous mass manmade disaster situation for more than 25 years, with thousands of people dead, maimed and mutilated, many missing or confined, thousands of children orphaned, and women widowed, a colossal damage to the property, and a damage to the cultural ethos including en-mass migration of a minority community ${ }^{13}$. As if this unrelenting manmade mass traumatic situation and it's sequel was not enough,a small picturesque village "Waltengo Nard" at the foothills of Pir Panchal range of Himalayas about 90km from Srinagar, the summer capital of Kashmir, was struck by a devastating snowstorm following continuous heavy snowfall for five consecutive days. ${ }^{7,18}$

The snowstorm was named "Snow Tsunami" by the Air Chief of India and the other rescue agencies. Almost 25\% $(\mathrm{n}=164)$ population perished within minutes. Since dead bodies could not be moved out to graveyard, 5-10 bodies had to be buried together in mass graves in the same houses where some of the injured and surviving people were still trapped. One-year longitudinal study of the snow storm disaster survivors by Margoob et al. in 2006 had revealed a very high level of psychological problems and psychiatric morbidity among the surviving population ${ }^{18}$. Disasters can have detrimental consequences at the individual and community level, altering the infrastructure of societies and causing both physical and psychological suffering among those affected. Mental health research has increasingly focused on the adverse consequences of disasters on the health of survivors but most of the research available so far from natural disaster related literature is confined to only short term impact of such catastrophes. So to advance our understanding of the consequences of disasters on survivor's mental health, by examining the possible sociodemographic vulnerabilities and psychosocial outcomes 10 years after storm disaster was undertaken as the objective of this research endeavor.

\section{Material and Methods:-}

\section{Study Design:-}

This was a cohort cross sectional study, the study group comprised of the young adults of the whole surviving population of the disaster affected area (exposed) at the Waltengo Nard, Qazigund.The control group included the population of snow storm unaffected area (unexposed) about $100 \mathrm{~km}$ away from the disaster site at Inder Nard,Kangan ,District Gandrbal with identical sociodemographic and socio cultural background

\section{Sample:-}

All the young adult snow storm disaster survivors of age between 19 years to 39 years were approached to be included in the study, after the households were enumerated with the help of key persons at the site. Similarly in the control population, households where included randomly and their corresponding age inmates were enrolled as study subjects. Informed consent was obtained from the from each subject included in the study. Those who refused to consent or could not be contacted were excluded. 
Tools:-

A semi-structured interview schedule specifically prepared for the study was used to collect information on the socio-demographic variables in both groups and the extent of exposure to snow storm disaster in the study group. Kuppuswamy's Socioeconomic Status Scale ${ }^{10}$ was used for determining socio-economic status . Oslo-3 Social Support Scale (OSS-3) was used to calculate social support ${ }^{3}$.Appropriate statistical tools to analyse the results were used.

Results:-

Table 1:- Present age wise make up (as on ending Oct.2016) of disaster survivors and Comparison population.

\begin{tabular}{|c|cc|cc|}
\hline & \multicolumn{2}{|c|}{ Disaster survivors } & \multicolumn{2}{c|}{ Comparison group } \\
\hline & $\mathrm{N} 494$ & $(100 \%)$ & $\mathrm{N} 228$ & $(100 \%)$ \\
\hline Adult males & 130 & $(26.31)$ & 79 & $(34.64)$ \\
\hline Adult females & 131 & $(26.51)$ & 65 & $(28.50)$ \\
\hline children & 233 & $(47.16)$ & 84 & $(36.84)$ \\
\hline
\end{tabular}

Table 2:- Sociodemographic profile of the study group and control population-I.

\begin{tabular}{|c|c|c|c|c|c|c|}
\hline \multirow[t]{2}{*}{ Variable } & \multicolumn{2}{|c|}{ Study group } & \multicolumn{2}{|c|}{ Control group } & \multirow[t]{2}{*}{$\mathrm{Z}$ value } & \multirow[t]{2}{*}{$P$ value } \\
\hline & N 139 & 6 age & $\mathrm{N} 7$ & $\%$ age & & \\
\hline \multicolumn{7}{|l|}{ Age } \\
\hline $19-25$ years & 60 & 43.16 & 34 & 47.88 & 0.65 & 0.51 \\
\hline 26-31 years & 37 & 26.62 & 21 & 29.57 & 0.45 & 0.65 \\
\hline $32-38$ years & 42 & 30.22 & 16 & 22.55 & 1.17 & 0.23 \\
\hline \multicolumn{7}{|l|}{$\underline{\operatorname{Sex}}$} \\
\hline Males & 70 & 50.35 & 42 & 59.15 & 1.20 & 0.22 \\
\hline Females & 69 & 49.65 & 29 & 40.85 & 1.20 & 0.22 \\
\hline \multicolumn{7}{|l|}{ Educational Status } \\
\hline $\begin{array}{l}\text { Primary School }\left(1^{\text {st }} \text { To } 5^{\text {th }}\right. \\
\text { Standard })\end{array}$ & 66 & 47.48 & 34 & 47.88 & 0.05 & 0.95 \\
\hline $\begin{array}{l}\text { Middle School }\left(6^{\text {th }} \text { To } 8^{\text {th }}\right. \\
\text { Std.) }\end{array}$ & 52 & 37.41 & 26 & 36.61 & 0.11 & 0.97 \\
\hline $\begin{array}{l}\text { High School }\left(9^{\text {th }} \& 10^{\text {th }}\right. \\
\text { Std.) }\end{array}$ & 15 & 10.79 & 8 & 11.26 & 0.10 & 0.92 \\
\hline $11^{\text {th }}$ class and above & 6 & 4.31 & 3 & 4.22 & 0.03 & 0.97 \\
\hline \multicolumn{7}{|l|}{ Family Type } \\
\hline Nuclear & 30 & 21.58 & 21 & 29.57 & 1.27 & 0.20 \\
\hline Extended Nuclear & 63 & 45.32 & 18 & 25.35 & 2.81 & 0.004 \\
\hline Joint & 46 & 33.93 & 33 & 46.47 & 1.89 & 0.06 \\
\hline
\end{tabular}

Table 3:- Socio demographic profile of study group and control population-II.

\begin{tabular}{|l|l|l|l|l|l|l|}
\hline Variable & \multicolumn{2}{|c|}{ Study group } & \multicolumn{2}{c|}{ Control group } & \multirow{2}{*}{ Z value } & \multirow{2}{*}{ P value } \\
\hline Socio-Economic Status & $\mathrm{N} 139$ & \multicolumn{2}{|l}{ N 71 } & \% age & & \\
\hline Upper & & & & & & \\
\hline Upper Middle & & & & & & \\
Lower Middle & 5 & 3.59 & 7 & 7.04 & NA & NA \\
\hline Upper Lower & 76 & 54.67 & 47 & 66.19 & 0.60 & 0.11 \\
\hline Lower & 58 & 41.72 & 12 & 16.90 & 3.61 & 50.05 \\
\hline Social Support & & & & & & \\
\hline Good/Fair & 40 & 28.77 & 28 & 39.43 & 1.56 & 0.11 \\
\hline Poor & 99 & 71.22 & 43 & 60.56 & 1.56 & 0.11 \\
\hline Birth Order & & & & & & \\
\hline Eldest & 20 & 14.38 & 15 & 21.12 & 1.23 & 0.21 \\
\hline Middle & 70 & 50.35 & 34 & 47.88 & 0.33 & 0.72 \\
\hline
\end{tabular}




\begin{tabular}{|l|l|l|l|l|l|l|}
\hline Youngest & 36 & 25.89 & 17 & 23.94 & 0.30 & 10.75 \\
\hline Only Child & 13 & 9.35 & 5 & 7.04 & 0.56 & 0.56 \\
\hline Source Of Income & & & & & & \\
\hline Labourer Cattle/Farming & 110 & 79.13 & 57 & 80.28 & 0.19 & 0.84 \\
\hline $\begin{array}{l}\text { Semi-Government/private } \\
\text { need based worker }\end{array}$ & 20 & 14.38 & 10 & 14.08 & 0.05 & 0.95 \\
\hline Government Job & 9 & 6.47 & 4 & 5.63 & 0.23 & 0.81 \\
\hline
\end{tabular}

\section{Discussion:-}

The studied population of Gujars (semi-nomadic) tribe had a comparable age wise distribution between the two groups as reflected by Table 1. Gujar are a pastoral agricultural ethnic group with populations in India and Pakistan and a small number in north-eastern Afghanistan. According to the 2011Census of India, Gujar is the most populous scheduled tribe in the state of Jammu and \&Kashmir having a population of 763,806. Though there were no statistically significant differences between the snow storm-exposed and comparison groups with regard to most of the demographic information, but as revealed by the result the study sample is mostly comprised of young adults belonging to the poorest strata of the society with lowest education level, families without any sustained or permanent source of income, poorest social support, (71.22\% in study group and $60.56 \%$ among the control group.)

Undesirably except for the initial 1-2 months after disaster, the survivors' real immediate and future concerns were never secured. Almost every year the extremely poor and marginalised disaster hit community continues to be subjected to severe re-traumatisation in winters when following a snow fall they are evacuated and rescued to safer places by the government agencies which has continued till this year's snow fall on $18^{\text {th }}$ January 2017 . The importance of psycho-social consequences need to be recognized earnestly so as to develop appropriate policy with relevant plan of action and integrate it into the overall disaster management strategy to meet the mental health needs of the disaster effected populations. For children, adolescents, and young adults response to disaster involves a complex interplay of pre-existing psychological vulnerabilities, stressors and nature of support in the aftermath.

The present study is a far-sighted one which aims to determine long term psychological morbidity among the surviving children and adolescents of this disaster affected area ten years after the snowstorm disaster. Since, sociodemographic factors also play a role in trauma vulnerability and resilience, therefore, the age group studied in this research was obviously more vulnerable sub group of the disaster hit population and has faced the brunt of the storm as young children and adolescents. This is consistent with the research that has suggested that younger children possess fewer strategies for coping with both the immediate disaster impact and its aftermath, and thus may suffer more severe emotional and psychological problems ${ }^{17}$ and adolescents are also known to suffer significant morbidity under such conditions ${ }^{19}$

Our study shows that people with lower educational level have higher psychiatric morbidity. This was in accordance with an earlier study by $\mathrm{Kar}_{\text {et }} \mathrm{al}^{8}$. These findings are also in aggrement with the findings of another study which found maximum morbidity $\left(34.1 \%\right.$ ) in less educated young population ${ }^{5}$, but nothing can be commented about the reported protective role of higher educational status in our studied group due to the harsh reality that more than $85 \%$ of the young adults studied by us were forced by unfavourable circumstances to abandon education before qualifying even before qualifying the $8^{\text {th }}$ Std . As recently observed by Kousky(2016) not only are disasters themselves stressful and frightening, but children suffer psychological harm from the damage to their homes and possessions; from migration; from the grief of losing loved ones; from seeing parents or caregivers undergo stress; from neglect and abuse; and from breakdowns in social networks, neighbourhoods, and local economies ${ }^{9}$ Disasters can interrupt children's education by displacing families, destroying schools, and pushing children into the labour force to help their families make ends meet in strained times. Reinforcing coping and resilience among the disaster survivors is also imperative.

The coping strategies adopted by our subjects to tackle the psychological distress were surrender to the will of God, sharing with relatives and family members, getting busy,using tobacco and other medication, and some of them could not define it.This resulted in their rationalising the event and hence,possibly, prevented them from much psychological distress.this observation is in aggrement with the observation reported by Margoob et al in the same population at one year post disaster period.${ }^{14}$ Spiritual help from faith healers,clergy and respected elders from the communitywas of immence help in helping survivors to come to terms with and live down the trauma.Eastern 
religions teach inevitability of fate, which helps survivors to accept and live beyond trauma. ${ }^{15}$ Spiritual involvement in the survivors of Waltengo also involved attachment to and obedience of local clergy (Imams) and spiritual leaders (Pirs). In many cases extreme avoidance or numbing of even desperate cases was significantly reduced, within a few sessions of advice and counselling by them.Integrating spiritual components as a part of the psychosocial interventions was rewarding in the management of many patients with severe post disaster psychopathology. ${ }^{14}$ Spiritual healers(Pirs)and clergy (Imams) have a central role in this process among socioeconomically deprived and educationally backward people, who in the absence of any mental health care service hold the pir in high reverence ${ }^{6}$ Psychotherapeutic intervention through the medium of spirituality actually contains some essential elements of cognitive behaviour therapy including informal administration of elements of prolonged exposure, stress inoculation therapy and cognitive reframing.

\section{Summary and Conclusion:-}

The following conclusions can be drawn from the study:-

$>$ The results indicate that disasters can have long standing effects on survivor's psychosocial well being and mental health even 10 years later .

$>$ Post trauma morbidity is more lasting in people with lesser support viz lower socioeconomic class, rural background and low education level.

$>$ Post trauma sequel need to be recognised in the study sample in view of having a high prevalence of trauma.

$>$ The positive coping methods and socio- cultural bonds and spirituality need to be further strengthened.

\section{Suggestions:-}

As reflected by the study, disasters can have a long term negative impact on the psychosocial well being of the survivors ,particularly the vulnerable groups such as children and adolescents. The interaction at the interface of society and environment in developing countries essentially determines the outcome of disasters. There is aneed to frame a timely and well framed policy to solve disaster related problems.Raising the awareness regarding the coping mechanisms for disasters especiaaly in the developing world should be given priority for measures of post disaster recovery .Attention needs to be paid to high risk groups and strong policy support and appropriate guidance mechanisms need to be put in place .

\section{References:-}

1. Benz,G.(1989) List of major natural disasters. 1960-1987. Earthquake and Volcanoes, 20, 226-228.

2. Bonanno et al Weighing the Costs of Disaster: Consequences, Risks, and Resilience in Individuals, Families, and Communities Psychological Science in the Public Interest 2010,11(1) 1-49

3. Dalgard OS. Explanation of OSS-3. European Public Health Information System (EUPHIX); 2008

4. Greca A M Children Experiencing Disasters: Prevention and Intervention In J. Hughes, A. M La Greca, \& J. C. Conoley (Eds.), Handbook of Psychological

5. Hoven CW, Duarte CS, Tucas CP, Wu P, Mandell DJ, Goodwin RD, Cohen M, Balaban 15 W'oodruff BA, Bin F, Musa GJ, Mei L, P Cantor PA, Aber JF, Cohen P, Susser E : Psychopathology Among New York City Public School Children 6 Months After September 11 Arch Gen Psychiatry. 2005;62:545-551.

6. Huda M, Margoob ALA et al. Pir, Faqir and psychotherapist: their role in psychosocial intervention of trauma. JK pract 2006; 13 (suppH ):s89-s93.

7. Hussain A and Margoob MA. Snow storm disaster - learning and experience: first three months. JK Practitioner, Vol.13,.Supplement 1, S26-S28 2006.

8. Kar N. Indian research on disaster and mental health, Indian J Psychiatry. 2010 Jan; 52(Suppl1): S286-S290.

9. Kousky C : Impact of Natural Disasters on Children,The Future of Children,2016; Vol 26; No. 1 , 73-92

10. Kumar N, Shekhar C, Kumar P, Kundu AS. Kuppuswamy's Socioeconomic Status Scale-Updating for 2007. Indian J Pediatr. 2007; 74: 1131-1132.

11. Lazarus, Philip J., Shane R. Jimerson, and Stephen E. Brock. "Responding to natural disasters: Helping children and families." National Association of School Psychologists (2003).

12. López-Ibor J JR, Disasters and mental health: New challenges for the psychiatric profession, The World Journal Of Biological Psychiatry Vol. 7 , Iss. 3,2006

13. Margoob M. A, Muhammad Mudasir Firdosi, Rakesh Banal. (2006)Community prevalence of trauma in South Asia-Experience from Kashmir. JK-Practitioner, Spl Supplement 1, Vol 13, , S14.

14. Margooh MA, Khan AY, Firdosi ATM, Ahmad SA, Shaukat T: One year longitudinal study of snowstorm survivors in Kashmir. JK Practitioner2006;13 (Suppl. 1);S29-S38 
15. Margoob M A, Firdosi ATM, Banal R, Khan AY, Malik YA, Ahmad SA, Hussain A, Aiajid A, Wani ZAi, Bother YH, AiugamilM, Khanday SA, Shah AIS: Community pre valence of trauma in South Asia Experience from Kashmir. JK-Practitioner 2006d:13 (Suppl I):S14-S 17.

16. Mercuri A and Angelique 11 la Children's responses to natural, technological, and na-tech disasters. Community Mental Health journal 2004:40(2): 167- 175.

17. Mezzich, J. E., \& Soto, N. R. M. (2016). Global perspectives and latin American experience on person-centred disaster response. disasters: mental health context and responses, 47. 18.Mushtaq A.Margoob, Akash Y Khan, M Mudasir Firdosi et al. (2006) One year longitudinal study of snowstorm disaster survivors in Kashmir. JKPractitioner, Spl Supplement 1, Vol 13, 2006, S29 .

18. Yule W,and Canterbury R:The Treatment of Post Traumatic Stress Disorder in Children and Adolscents:International Review of Psychiatry.1994:6:141-151 